\title{
Sleep quality and associated factors during the COVID-19 epidemic among community non-medical anti-epidemic Workers of Wuhan, China
}

Guanglin $\mathrm{Si}^{1+}$, Yi Xu ${ }^{1+}$, Mengying $\mathrm{Li}^{1 \dagger}$, Yuting Zhang ${ }^{2+}$, Shuzhen Peng ${ }^{3 *}$ and Xiaodong $\operatorname{Tan}^{1,4^{*}}$ (D)

\begin{abstract}
Background: Since the outbreak of Coronavirus Disease 2019 (COVID-19) in December 2019, community nonmedical anti-epidemic workers have played an important role in the prevention of COVID-19 in China. The present study aimed to assess sleep quality and its associated factors among community non-medical anti-epidemic workers.

Method: A survey was conducted using anonymous online questionnaire to collect information from 16 March 2020 to 24 March 2020. A total of 474 participants were included, with a $94.23 \%$ completion rate. The questionnaire contained demographic data, physical symptoms, and contact history with COVID-19. The researchers assessed perceived social support by the Multidimensional Scale of Perceived Social Support (MSPSS), assessed perceived stress by the Perceived Stress Scale (PSS), and measured sleep quality by the Pittsburgh Sleep Quality Index (PSQI) questionnaire.

Results: Among the participants, 46.20\% reported poor sleep quality. A binary logistic regression revealed that having educational background of junior college or above, being a member of the police force, having contacted individuals with confirmed or suspected COVID-19 infection, having chronic disease(s), having illness within 2 weeks, and having high or moderate perceived stress were significant factors associated with an increased risk of poor sleep quality.

Conclusion: Demographic factors, physical symptoms, history of contact with COVID-19, and perceived stress are significantly associated with poor sleep quality of community non-medical anti-epidemic workers. Thus, targeting these factors might be helpful in enhancing sleep quality of community workers.
\end{abstract}

Keywords: Sleep quality, Community non-medical anti-epidemic workers, COVID-19, Wuhan

\footnotetext{
* Correspondence: 13647226126@163.com; 00300469@whu.edu.cn

† Guanglin Si, Yi Xu, Mengying Li and Yuting Zhang are authors contributed

equally to this manuscript and were listed as co-first authors.

${ }^{3}$ Huangpi District People's Hospital, Wuhan 430300, China

${ }^{1}$ School of Health Sciences, Wuhan University, Wuhan 430071, China

Full list of author information is available at the end of the article
}

(c) The Author(s). 2021 Open Access This article is licensed under a Creative Commons Attribution 4.0 International License, which permits use, sharing, adaptation, distribution and reproduction in any medium or format, as long as you give appropriate credit to the original author(s) and the source, provide a link to the Creative Commons licence, and indicate if changes were made. The images or other third party material in this article are included in the article's Creative Commons licence, unless indicated otherwise in a credit line to the material. If material is not included in the article's Creative Commons licence and your intended use is not permitted by statutory regulation or exceeds the permitted use, you will need to obtain permission directly from the copyright holder. To view a copy of this licence, visit http://creativecommons.org/licenses/by/4.0/ The Creative Commons Public Domain Dedication waiver (http://creativecommons.org/publicdomain/zero/1.0/) applies to the data made available in this article, unless otherwise stated in a credit line to the data. 


\section{Background}

Since the outbreak of Coronavirus Disease 2019 (COVID-19) in December 2019, around the world, the disease's social consequences of mass confinement at home have caused much stress [1,2]. The community anti-epidemic workers, both medical and non-medical workers, have played an important role in the community-based prevention of COVID-19 in China. The non-medical workers mainly participated in "population mobility control" and "community digital management". For example, the workers collected basic information about residents in a door-to-door way, shifted patients with restrictions on the access to each community, and delivered living supplies to residents who were home-quarantined [3, 4]. However, in accordance with the reports on anti-epidemic nurses during COVID-19 and MERS-CoV [5, 6], continuous working under stressful circumstances for many hours and managing potential health risks could have a major influence on the mental health and sleep quality of non-medical anti-epidemic workers [7].

The existing literature regarding associations among individuals' stress, social support, and health outcomes indicates the potential influence of moderating factors [8]. The community non-medical anti-epidemic workers are exposed to working environments with low resources and high working demands, high stress, and greater physical and psychological stress, which can adversely affect their health status and sleep quality. Sleep is an important determinant of health, and it is essential for the maintenance of physical and mental health [9]. Sleep disturbance can lead to poor concentration and finances [10] and may increase individuals' morbidity and mortality [11]. Good sleep quality can help improve immunity against viral infection [12]. Therefore, it is important for researchers to study modifiable factors that are associated with sleep quality.

Recent studies on the epidemic of COVID-19 have been concentrated on clinical epidemiology, prevention, and treatment [13-15]. Few researchers have investigated the sleep quality and other mental-health related issues of community non-medical anti-epidemic workers during the epidemic of COVID-19. Therefore, we conducted the present study to close this gap and better understand sleep quality among community nonmedical anti-epidemic workers and relevant factors in Wuhan, China.

\section{Method}

\section{Participants and procedure}

The survey was conducted from 16 March 2020 to 24 March 2020 by anonymous online questionnaires. The convenience-sampling method was used. The researchers randomly selected 15 communities in Wuhan,
China. Considering the scale of each community, the researchers selected 30 members for each. The sample size was amplified according to the inefficiency of $10 \%$, and the final expected sample size was 495 . The inclusion criteria and exclusion criteria were as follows: (a) Inclusion criteria: (1) The worker had at least 1 month's experience in anti-epidemic work. (2) The worker had not suffered from mental illness and had not been stimulated by major adverse life events. (3) The worker was willing to participate in the survey. (b) Exclusion criteria: (1) The worker had less than 1 month's experience in anti-epidemic work. (2) The worker was a shift worker. (3) The worker was unwilling to participate in the survey.

A total of 503 community non-medical anti-epidemic workers in Wuhan, China, participated in the survey. After excluding the questionnaires with repeated filling (ID and basic information are completely consistent) or suspected false answers, the study finally included a total of 474 valid samples, with a $94.23 \%$ completion rate.

\section{Instrument}

The structured questionnaire comprised of six areas: (1) Demographic variables, including sex, age, educational background, marital status, occupation, and work experience. (2) Contact with an individual with confirmed or suspected COVID-19 infection. (3) Health-related factors, including chronic disease and illness within 2 weeks. Chronic disease was evaluated through the participant's response ("yes" or "no") to the question "if you have been diagnosed with diabetes, hypertension, heart disease, arthritis, migraine, asthma, thyroid disease, heart disease, thrombosis, bronchitis/emphysema, osteoporosis, cancer, stomach/peptic ulcer, cerebrovascular disease or other major physical diseases", which was similar to what Scott described in a previous study [16]. The present researchers defined illness within 2 weeks as acute sickness lasting for the past 2 weeks. (4) Perceived social support, measured by the Multidimensional Scale of Perceived Social Support (MSPSS), which was developed by Zimet et al. in 1990 [17]. The MSPSS scale comprised of 12 items, which are rated on a seven-point scale $(1=$ very strongly disagree, $7=$ very strongly agree $)$. The total perceived social support score was obtained by summing the responses to each item, and a total MSPSS score $<32$ indicated serious perceived social support problems, a score $\geq 32$ and $<50$ indicated some perceived social support problems, and a score $>50$ indicated no perceived social support problem. The Chinese version of the MSPSS has demonstrated good reliability and validity [18]. (5) Perceived stress, measured by the Perceived Stress Scale (PSS), which was developed by Cohen et al. in 1983 [19]. The PSS scale comprised of 10 items with a five-point rating scale $(0=$ never, $4=$ 
always), and the total score of PSS ranged from 0 to 40 . A total PSS score $>19$ indicated high perceived stress, a total score $>13$ and $\leq 19$ indicated moderate perceived stress, and a total score $\leq 13$ indicated low perceived stress. Previous researchers had examined the Chinese version of the PSS and documented favorable results [20]. (6) Sleep quality, measured by the Pittsburgh Sleep Quality Index (PSQI) questionnaire, which was developed by Buysse et al. in 1989 [21]. The PSQI scale comprised of seven dimensions: subjective sleep quality, sleep latency, sleep duration, habitual sleep efficiency, sleep disturbance, use of sleep medication, and daytime dysfunction. Each dimension was scored on a scale from 0 to 3 , with a total score ranging from 0 to 21 . The Chinese version of the PSQI has good reliability and validity in the Chinese population [22]. According to a previous study [21], a total PSQI score $\leq 5$ indicated good sleep quality, and a total score $>5$ indicated poor sleep quality.

\section{Statistical analysis}

The present researchers conducted all data analysis by using SPSS version 20.0 (IBM Corp., Armonk, NY, USA). Data were presented by frequencies and percentages. Chi-squared tests were used to examine the rate of poor sleep quality in different groups and to choose independent variables for a binary logistic regression analysis. Independent variables with $p<0.05$ were included in the binary logistic regression analysis (Forward: LR). Finally, the present study identified variables that had a significant association with poor sleep quality on the basis of odds ratio (OR) and 95\% confidence interval (95\% CI). The independent variables included sex, age category, marital status, educational background, occupation, work experience, contact with individuals with confirmed or suspected COVID-19 infection, chronic disease, illness within 2 weeks, perceived social support, and perceived stress. The dependent variable was sleep quality. All variables were treated as categorical factors, and $p<0.05$ (two-sides) was considered as statistically significant.

\section{Results}

\section{Participant characteristics}

Of the participants, $63.71 \%$ were male, and $36.29 \%$ were female. Ages ranged from 20 to 65 years with an average of $38.94 \pm 10.18$ years. The percentage of participants whose educational background was junior college or above was $73.42 \%$. The percentage of participants who were married was $68.14 \%$. The percentage of participants who had at least 10 years of work experience was $35.44 \%$. A majority of participants were in the police force (81.01\%). A majority of participants did not report a problem with social support (83.76\%). Almost half of the participants $(48.95 \%)$ perceived their stress level as low. Furthermore, the percentage of participants who had contact with the individuals with confirmed or suspected COVID-19 infection was only $16.24 \%$. About a quarter of the participants had one or more chronic diseases $(25.53 \%)$. Less than a third of the participants had an illness within 2 weeks (28.06\%) (Table 1$)$.

\section{Group comparison of sleep quality}

The results of the chi-square test are shown in Table 1. Educational background $(p=0.000)$, occupation $(p=$ $0.021)$, work experience $(p=0.037)$, contact with individuals with confirmed or suspected COVID-19 infec$\operatorname{tion}(p=0.002)$, chronic disease $(p=0.000)$, illness within 2 weeks $(p=0.000)$, and perceived stress $(p=0.000)$ were all associated with sleep quality; participants with educational background of junior college or above, members of the police force, participants with at least 10 years of work experience, participants who had contacted with individuals with confirmed or COVID-19 infection, participants who had chronic disease, participants who had been ill within 2 weeks, and participants with high perceived stress were more likely to report poor sleep quality.

\section{Factors associated with sleep quality}

The present researchers included all significant variables in the binary logistic regression analysis. As Table 2 shows, after adjusting for education level, occupation, work experience, contact with an individual with confirmed or suspected COVID-19 infection, chronic disease, illness within 2 weeks, and perceived stress, the present researchers found that the participants with educational background of junior college or above were 2.38 times more likely to report poor sleep quality than those with educational background of high school or technical secondary school $(p<0.01)$. Compared with volunteers, the members of the police force were 2.07 times more likely to report poor sleep quality $(p<0.01)$. Participants with at least 10 years of work experience were 1.61 times more likely to report poor sleep quality than those with $\leq 3$ years of work experience $(p<0.05)$, and they were 2.22 times more likely to report poor sleep quality than those with 7-9 years of work experience $(p<0.05)$. Participants who had contacted with an individual with confirmed or suspected COVID-19 infection were 2.19 times more likely to report poor sleep quality as those who had not $(p<0.01)$. Participants who had chronic disease were 2.37 times more likely to report poor sleep quality than those who did not $(p<0.01)$. Participants who had been ill within 2 weeks were 4.17 times more likely to report poor sleep quality than those who had not $(p<0.01)$. Compared with the participants with low perceived stress, those with high perceived stress were 
Table 1 Comparison of sleep quality among participants of different groups $(n=474)$

\begin{tabular}{|c|c|c|c|c|}
\hline Category & Group & $\begin{array}{l}\text { Good Rate (n/ } \\
\%)\end{array}$ & $\begin{array}{l}\text { Poor Rate }(\mathrm{n} / \\
\%)\end{array}$ & $p$ \\
\hline \multirow[t]{2}{*}{ Sex } & male & $159(52.65)$ & $143(47.35)$ & 0.506 \\
\hline & female & $96(55.81)$ & $76(44.19)$ & \\
\hline \multirow[t]{3}{*}{ Age category (years) } & $20-35$ & $105(54.69)$ & $87(45.31)$ & 0.489 \\
\hline & $36-50$ & $120(55.05)$ & $98(44.95)$ & \\
\hline & $>50$ & $30(46.88)$ & $34(53.13)$ & \\
\hline \multirow[t]{3}{*}{ Marital status } & unmarried & $64(52.89)$ & $57(47.11)$ & 0.932 \\
\hline & married & $174(53.87)$ & $149(46.13)$ & \\
\hline & divorced/widowed & $17(56.67)$ & $13(43.33)$ & \\
\hline \multirow[t]{3}{*}{ Educational background } & junior middle school or below & $13(65.00)$ & $6(35.00)$ & 0.000 \\
\hline & $\begin{array}{l}\text { high school/technical secondary } \\
\text { school }\end{array}$ & $74(69.16)$ & $33(30.84)$ & \\
\hline & junior college or above & $168(48.28)$ & $180(51.72)$ & \\
\hline \multirow[t]{3}{*}{ Occupation } & community workers & $11(61.11)$ & 7 (38.89) & 0.021 \\
\hline & polices & $195(50.78)$ & $189(49.22)$ & \\
\hline & volunteers & $49(68.06)$ & $23(31.94)$ & \\
\hline \multirow[t]{4}{*}{ Work experience (years) } & $\leq 3$ & $94(57.67)$ & $69(42.33)$ & 0.037 \\
\hline & $4-6$ & $43(53.75)$ & $37(46.25)$ & \\
\hline & $7-9$ & $41(65.79)$ & $22(34.92)$ & \\
\hline & $\geq 10$ & $77(45.83)$ & $91(54.17)$ & \\
\hline \multirow{2}{*}{$\begin{array}{l}\text { Contact with individuals with confirmed or suspected COVID-19 } \\
\text { infection }\end{array}$} & yes & 29 (37.66) & $48(62.34)$ & 0.002 \\
\hline & no & $226(56.93)$ & $171(43.07)$ & \\
\hline \multirow[t]{2}{*}{ Chronic disease } & yes & $46(30.02)$ & 75 (61.98) & 0.000 \\
\hline & no & $209(59.21)$ & $144(40.79)$ & \\
\hline \multirow[t]{2}{*}{ Illness within 2 weeks } & yes & $39(29.32)$ & $94(70.68)$ & 0.000 \\
\hline & no & $216(63.34)$ & $125(36.66)$ & \\
\hline \multirow[t]{3}{*}{ Perceived Social support } & serious problems & $3(50.00)$ & $3(50.00)$ & 0.053 \\
\hline & some problems & $29(40.85)$ & $42(59.15)$ & \\
\hline & no problem & $223(56.17)$ & $174(43.83)$ & \\
\hline \multirow[t]{3}{*}{ Perceived stress } & high & $27(25.00)$ & $81(75.00)$ & 0.000 \\
\hline & moderate & $56(41.79)$ & $78(58.21)$ & \\
\hline & low & $172(74.14)$ & $60(25.86)$ & \\
\hline
\end{tabular}

8.60 times more likely to report poor sleep quality $(p<$ 0.01 ), and those with moderate perceived stress were 3.99 times more likely to report poor sleep quality $(p<$ $0.01)$.

\section{Discussion}

In the present study, the researchers explored the associated factors of poor sleep quality among community non-medical anti-epidemic workers in Wuhan, China, during the COVID-19 epidemic. The percentage of the participants who reported poor sleep quality was $46.20 \%$, which was higher than the previously reported among the residents aged 15-69 years in China (35.74\%) [23]. Poor sleep quality is a common problem in modern society [24], and during the COVID-19 epidemic, the community non-medical anti-epidemic workers were exposed to more risk factors that are related to sleep quality.

The present researchers found that the participants whose educational background was high school or technical secondary school were less likely to report poor sleep quality than those whose educational background was junior college or above. Moreover, the members of the police force were more likely to report poor sleep quality than volunteers. This finding is different from the based on a general population of Italian participants in a previous study [25]. A possible reason for this discrepancy is that the participants whose educational 
Table 2 Binary logistic regression analysis on factors associated with poor sleep quality $(n=474)$

\begin{tabular}{|c|c|c|c|}
\hline Variables & S.E. & OR & $95 \% \mathrm{Cl}$ \\
\hline \multicolumn{4}{|c|}{ Education background (junior college and above as reference) } \\
\hline Junior middle school or below & 0.51 & 0.43 & $0.16-1.16$ \\
\hline High school/technical secondary school & 0.24 & 0.42 & $0.26-0.66^{* *}$ \\
\hline \multicolumn{4}{|l|}{ Occupation (volunteers as reference) } \\
\hline community workers & 0.55 & 1.36 & $0.47-3.95$ \\
\hline polices & 0.27 & 2.07 & $1.21-3.52^{* *}$ \\
\hline \multicolumn{4}{|l|}{ Work experience (years) ( $\geq 10$ as reference) } \\
\hline$\leq 3$ & 0.22 & 0.62 & $0.40-0.96^{*}$ \\
\hline $4-6$ & 0.27 & 0.73 & $0.43-1.24$ \\
\hline $7-9$ & 0.31 & 0.45 & $0.25-0.83^{*}$ \\
\hline
\end{tabular}

Contact with individuals with confirmed or suspected COVID-19 infection (no as reference)

Yes

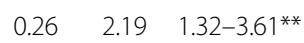

Chronic disease (no as reference)

Yes

$0.22 \quad 2.37 \quad 1.55-3.62^{* *}$

Illness within 2 weeks (no as reference)

Yes

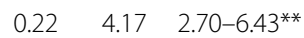

Perceived stress (low as reference)

\begin{tabular}{llll} 
High & 0.27 & 8.60 & $5.09-14.54^{* *}$ \\
Moderate & 0.231 & 3.99 & $2.54-6.27^{* *}$ \\
Constant & 0.101 & 0.76 & - \\
\hline
\end{tabular}

Adjusted for education level, occupation, work experience, contacted with an individual with confirmed or suspected COVID-19 infection, chronic disease, illness within 2 weeks, and perceived stress. S.E. standard error, OR odds ratio, 95\% Cl 95\% confidence interval

*: $P<0.05,{ }^{* *}: P<0.01$

background was junior college or above and those who were members of the police force always undertake more anti-epidemic duties in the community during the COVID-19 epidemic, which would increase their negative emotions and stress, resulting in poor sleep quality. The present results suggested that participants who had contact with individuals with confirmed or suspected COVID-19 infection were more likely to report poor sleep quality. COVID-19 could transmit from human to human among close contacts [13]. Thus, contact with individuals with confirmed or suspected COVID-19 infection would obviously increase the risk of infection and psychological pressures [26], which leads to psychological problems and poor sleep quality. In terms of health status, the present researchers found that chronic disease and illness within 2 weeks were associated with poor sleep quality, which is similar to the findings from previous studies based on general populations [27, 28]. Chronic disease and illness within 2 weeks would definitely affect an individual's quality of life, which has a close correlation with sleep quality [29].
Consistent with the previous findings from community residents [30], the present study manifested that perceived stress was an important factor related to sleep quality. Perceived stress is part of the individual's psychological response after perceiving and evaluating a threatening stimulus around. When the individual under stress, the psychological threats or confusions will arise following the cognitive evaluation, lead to physical and psychological illnesses, such as poor sleep quality [31,32].

The present study not only supplements previous studies, but also offers information about the community non-medical anti-epidemic workers. It examined multiple factors that are associated with sleep quality, such as demographic variables, health-related factors, social support, and perceived stress. Meanwhile, the questionnaire (PSQI) used in this study is reliable and can reflect individuals' real sleep quality of the past month.

Nevertheless, the present study also has some limitations. First, although the sample size is not sufficient, with 15 communities were being included. Second, because the survey was conducted during the COVID-19 epidemic, the present researchers could not perform face-to-face interviews, and the data may not reflect the real situation of the participants. Third, the cause-effect relationship cannot be established because of the nature of cross-sectional design. Fourth, sleep quality can be influenced by occupation and life stresses, which no information on common variables were collected to assess the occupational impact.

\section{Conclusion}

The present study revealed that community non-medical anti-epidemic workers who were members of the police force, workers with educational background of junior college or above, workers who had contact with individuals with confirmed or suspected COVID-19 infection, workers who had chronic disease(s), workers who had an illness within 2 weeks, and workers who had high or moderate perceived stress were more likely to report poor sleep quality. Therefore, the community nonmedical anti-epidemic workers are required to follow appropriate personal-protection procedures and conduct psychological interventions through psychological lectures.

\section{Abbreviations}

COVID-19: Coronavirus disease 2019; MSPSS: Multidimensional Scale of Perceived Social Support; PSS: Perceived Stress Scale; PSQI: Pittsburgh Sleep Quality Index; SD: Standard deviation; OR: Odds ratio; Cl: Confidence interval

\section{Acknowledgments}

The authors thank the community non-medical anti-epidemic workers who participated in the survey, and we acknowledge TopEdit LLC for the linguistic editing and proofreading during the preparation of this manuscript. 


\section{Authors' contributions}

The author contributions were as follows: G. S. designed the survey, analyzed data and wrote the manuscript; $Y$. X. designed the survey, collected the data and wrote the manuscript; M. L. modified the manuscript; Y. Z. analyzed the data and wrote the manuscript; S. P. edited the manuscript; X. T. edited the manuscript. All authors have read and approved the manuscript in its final form.

\section{Funding}

This research received no external funding.

\section{Availability of data and materials}

The datasets used and/or analyzed during the current study are available from the corresponding author on reasonable request.

\section{Declarations}

\section{Ethics approval and consent to participate}

The ethics committee of Wuhan University approved this study. Written informed consent was obtained from each participants before the survey, all participants voluntarily gave their informed consent to participate in the study. The procedures of this study complied with the provisions of the Declaration of Helsinki regarding research on Human participants.

\section{Consent for publication}

Not applicable.

\section{Competing interests}

The authors declare that they have no competing interests.

\section{Author details}

${ }^{1}$ School of Health Sciences, Wuhan University, Wuhan 430071, China. ${ }^{2}$ School of Nursing, Shenzhen University, Shenzhen 518037, China. ${ }^{3}$ Huangpi District People's Hospital, Wuhan 430300, China. "Wuchang University of Technology, Wuhan 430223, China.

Received: 19 May 2020 Accepted: 18 June 2021

Published online: 30 June 2021

\section{References}

1. Ebrahim SH, Ahmed QA, Gozzer E, Schlagenhauf P, Memish ZA. COVID-19 and community mitigation strategies in a pandemic. BMJ. 2020;368:m1066.

2. Wu ZY, McGoogan JM. Characteristics of and important lessons from the coronavirus disease 2019 (COVID-19) outbreak in China summary of a report of 72314 cases from the Chinese Center for Disease Control and Prevention. JAMA. 2020;323(13):1239-42. https://doi.org/10.1001/jama.2020.2648.

3. Zhang YH, Zhao Q, Hu B. Community-based prevention and control of COVID-19: experience from China. Am J Infect Control. 2020;48(6):716-7. https://doi.org/10.1016/j.ajic.2020.03.012.

4. Guo Y, Li Y, MonroeWise A, Yeung SCJ, Huang Y. A dynamic residential community-based quarantine strategy: China's experience in fighting COVID-19. Infect Control Hosp Epidemiol. 2020;41(11):1363-4. https://doi. org/10.1017/ice.2020.172

5. Tu ZH, He JW, Zhou N. Sleep quality and mood symptoms in conscripted frontline nurse in Wuhan, China during COVID-19 outbreak: a cross-sectional study. Medicine 2020;99(26):e20769. https://doi.org/10.1097/MD.0000000000020769.

6. Park JS, Lee EH, Park NR, Choi YH. Mental health of nurses working at a government-designated hospital during a MERS-CoV outbreak: a crosssectional study. Arch Psychiatr Nurs. 2018;32(1):2-6. https://doi.org/10.1016/ j.apnu.2017.09.006

7. $L i \mathrm{CH}$, Tan CX, Wu AH, Gao CQ. COVD-19: the role of community in China's response. J R Soc Med. 2020;113(7):280-1. https//doi.org/10.1177/0141076820935344.

8. Tas C, Brown EC, Eskikurt G, Irrnak S, Aydin O, Esen-Danaci A, et al. Cortisol response to stress in schizophrenia: associations with oxytocin, social support and social functioning. Psychiatry Res. 2018;270:1047-52. https://doi org/10.1016/j.psychres.2018.05.011.

9. Zhang HQ. Influence of key teachers' working pressure and resiliency on mental health in primary and middle school. Chin J Sch Health. 2010;31(8): $941-2$.

10. Lou JF, Zhu GX, Zhao QH, Guo QH, Meng HJ, Hong Z, et al. Prevenlence and risk factors of poor sleep quality among Chinese elderly in an urban community: results from Shanghai aging sutdy. PLoS One. 2013;8(11):e81261.
11. Kripke DF, Garfinkel L, Wingard DL, Klauber MR, Marler MR. Mortality associated with sleep duration and insomnia. Arch Gen Psychiatry. 2002; 59(2):131-6. https://doi.org/10.1001/archpsyc.59.2.131.

12. Gamaldo CE, Shaikh AK, Mcarthur JC. The sleep-immunity relationship. Neurol Clin. 2012;30(4):1313-43. https://doi.org/10.1016/j.ncl.2012.08.007.

13. Li Q, Guan XH, Wu P, Wang XY, Zhou L, Tong YQ, et al. Early transmission dynamics in Wuhan, China, of novel coronavirus-infected pneumonia. N Engl J Med. 2020;382(13):1199-207. https://doi.org/10.1056/NEJMoa2001316.

14. Guan WJ, Ni ZY, Hu Y, Liang WH, Ou CQ, He JX, et al. Clinical characteristics of coronavirus disease 2019 in China. N Engl J Med. 2020;382(18):1708-20. https://doi.org/10.1056/NEJMoa2002032.

15. Bauchner H, Fontanarosa PB. Randomized clinical trials and COVD-19: managing expectations. JAMA. 2020;323(22):2262-3. https://doi.org/10.1001/jama.2020.8115.

16. Scott D, Burke K, Williams S, Happell B, Canoy D, Ronan K. Increased prevalence of chronic physical health disorders in Australians with diagnosed mental illness. Aust N Z J Public Health. 2012;36(5):483-6. https:// doi.org/10.1111/j.1753-6405.2012.00916.x.

17. Zimet GD, Powell SS, Farley GK, Werkman S, Berkoff KA. Psychometric characteristics of the multidimensional scale of perceived social support. J Pers Assess. 1990;55(3):610-7. https://doi.org/10.1207/s15327752jpa5503\&4_17.

18. Wang XD, Wang XL, Ma H. Perceived social support scale(supplement). Beijing: Chinese Mental Health Journal; 1999.

19. Cohen S, Kamarck T, Mermelstein R. A global measure of perceived stress. J Health Soc Behav. 1983;24(4):385-96. https://doi.org/10.2307/2136404.

20. Wang Z, Chen J, Boyd JE, Zhang H, Jia X, Qiu J, et al. Psychometric properties of the Chinese version of the perceived stress scale in policewomen. PLoS One. 2011;6(12):e28610. https://doi.org/10.1371/journal.pone.0028610.

21. Buysse DJ, Reynolds CF, Monk TH, Berman SR, Kupfer DJ. The Pittsburghl sleep quality index: a newinstrument for psychiatric practice and research. Psychiatry Res. 1989;28(2):193-213. https://doi.org/10.1016/0165-1781(89)90047-4.

22. Tsai PS, Wang MY, Su CT, Yang TT, Huang CJ, Fang SC. Psychometric evaluation of the Chinese version of the Pittsburgh sleep quality index(CPSQI) in primary insomnia and control subjects. Qual Life Res. 2005; 14(8):1943-52. https://doi.org/10.1007/s11136-005-4346-x.

23. Yin $P$, Zhang $M$, Li Y Y, Jiang $Y$, Wang LM, Zhao WH. A study on risk factors for poor sleep quality among Chinese residents aged 15-69 years. Chin J Prev Contr Chron Dis. 2011;19(3):224-5.

24. Bonnet $\mathrm{MH}$, Arand $\mathrm{DL}$. Clinical effects of sleep fragmentation versus sleep deprivation. Sleep Med Rev. 2003;7(4):297-310. https:/doi.org/10.1053/smrv.2001.0245.

25. Costi S, Paltrinieri S, Bressi B, Fugazzaro S, Rossi PG, Mazzini E. Poor sleep during the first peak of the SARS-CoV-2 pandemic: a cross-sectional study. Int J Environ Res Public Health. 2021;18(1):306. https://doi.org/10.3390/ijerph18010306.

26. Zhong BL, Luo W, Li HM, Zhang QQ, Liu XG, Li WT, et al. Knowledge, attitudes, and practices towards COVID-19 among Chinese residents during the rapid rise period of the COVID-19 outbreak: a quick online cross-sectional survey. Int J Biol Sci. 2020;16(10):1745-52. https://doi.org/10.7150/ijbs.45221.

27. Haseli-Mashhadi N, Dadd T, Pan A, Yu ZJ, Lin X, Franco OH. Sleep quality in middle-aged and elderly Chinese: distribution, associated factors and associations with cardio-metabolic risk factors. BMC Public Health. 2009;9(1): 130. https://doi.org/10.1186/1471-2458-9-130.

28. Zhang HS, Li Y, Mo HY, Qiu DX, Zhao J, Luo JL, et al. A community-based cross-sectional study of sleep quality in middle-aged and older adults. Qual Life Res. 2017;26(4):923-33. https://doi.org/10.1007/s11136-016-1408-1.

29. Zeithofer J, Schmeiser-Rieder A, Tribl G, Rosenberger A, Bolitschek J, Kapfhammer G, et al. Sleep and quality of life in the Austrian population. Acta Neurol Scand. 2000; 102(4):249-57. https:/doi.org/10.1034/j.1600-0404.2000.102004249x.

30. Liu X, Liu C, Tian X, Zou G, Li G, Kong L, et al. Associations of perceived stress, resilience and social support with sleep disturbance among community-dwelling adults. Stress Health. 2016;32(5):578-86. https://doi. org/10.1002/smi.2664.

31. Yang YZ. Research on psychological pressure of urban population in social transformation. Chin J Epidemio. 2002;23(6):473-5.

32. Folkman S, Lazarus RS, Dunkelschetter C, Delongis A, Gruen RJ. Dynamics of a stressful encounter: cognitive appraisal, coping, and encounter outcomes. J Pers Soc Psychol. 1986;50(5):992-1003. https://doi.org/10.1037/0022-3514.50.5.992.

\section{Publisher's Note}

Springer Nature remains neutral with regard to jurisdictional claims in published maps and institutional affiliations. 